\title{
Reinforcement effectiveness in composites evaluated by low load acoustic emission
}

Kalliopi-Artemi Kalteremidou, Eleni Tsangouri, Lincy Pyl and Dimitrios G. Aggelis Dept. of Mechanics of Materials and Constructions (MEMC) - Vrije Universiteit Brussel (VUB), Pleinlaan 2, Brussels 1050, Belgium.

\section{ASEC 2020}

1st International Electronic Conference on Applied Sciences 10-30 NOVEMBER 
Fracture mode determination=What is the weakest link of our system?

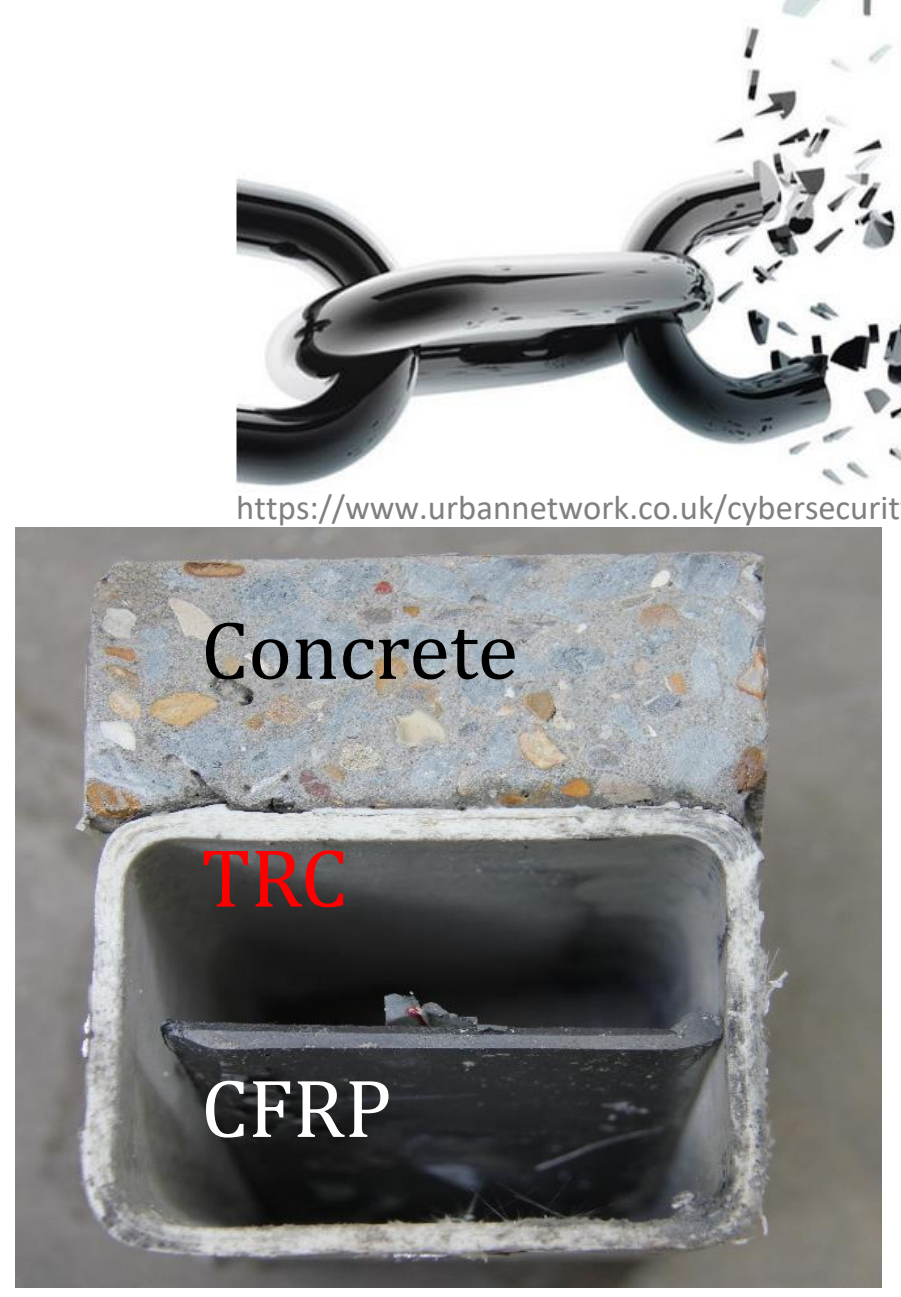

Possible fracture mechanisms:

- Crushing of concrete

- Debonding between

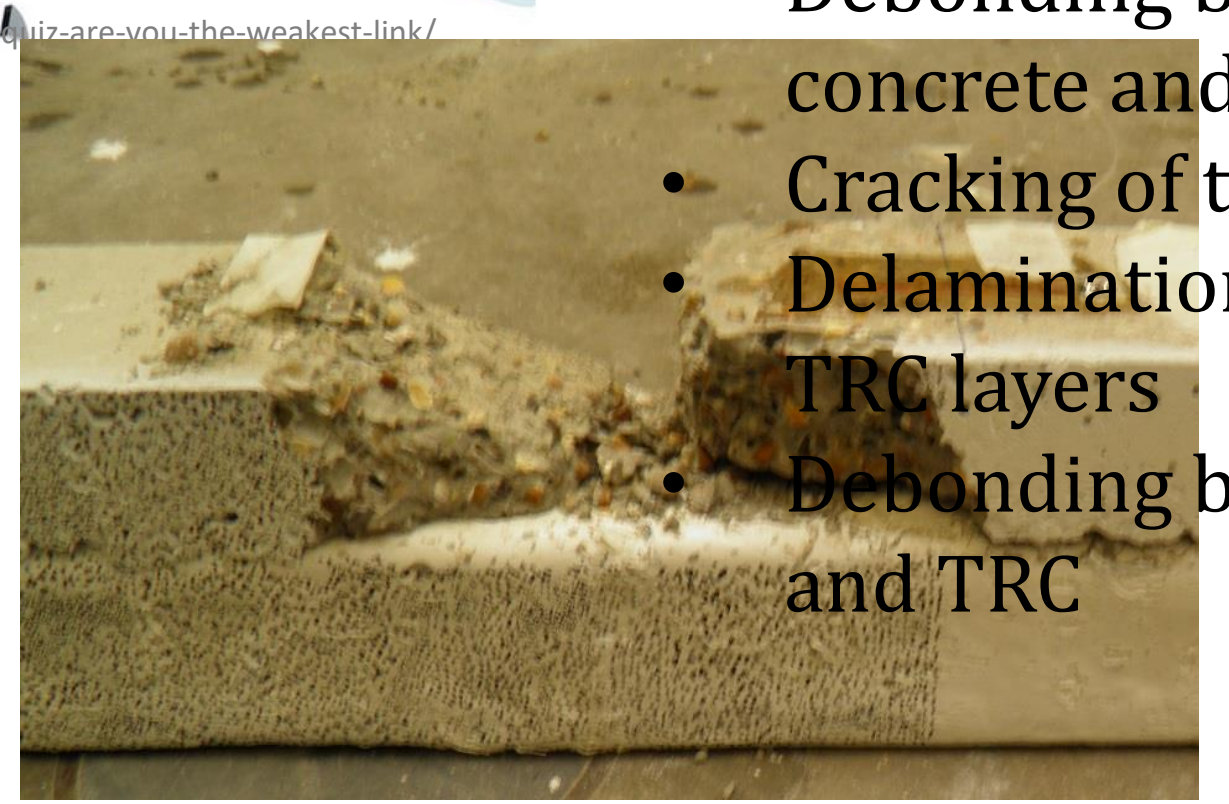

Helps to characterize the type of damage in heterogeneous components and improve the design and final properties (strength) 
In other words... Can AE of early loading stages indicate the effectiveness of reinforcement (goodness of bonding)?

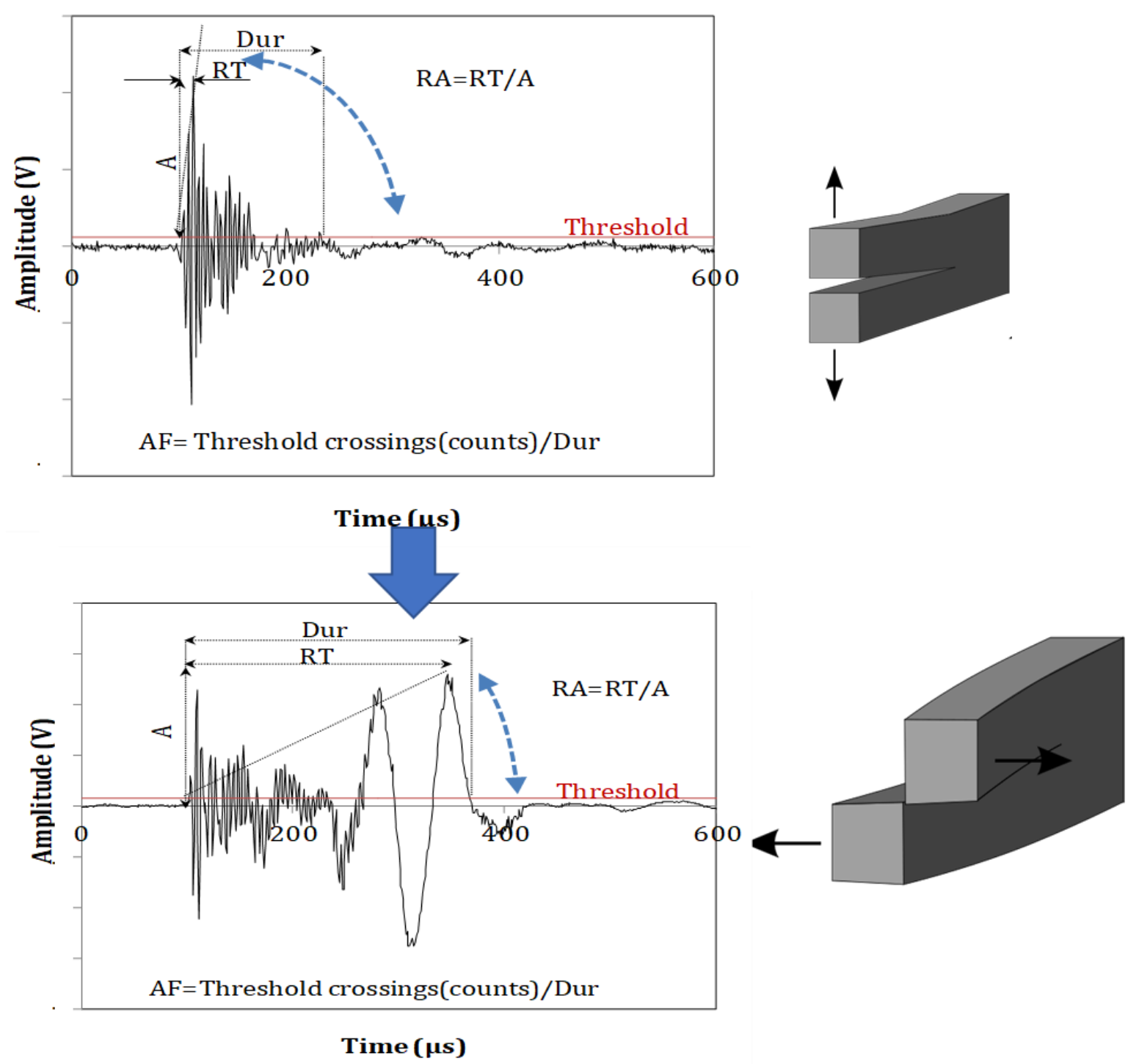




\section{Numerical simulations confirm relation between AE wave and source}
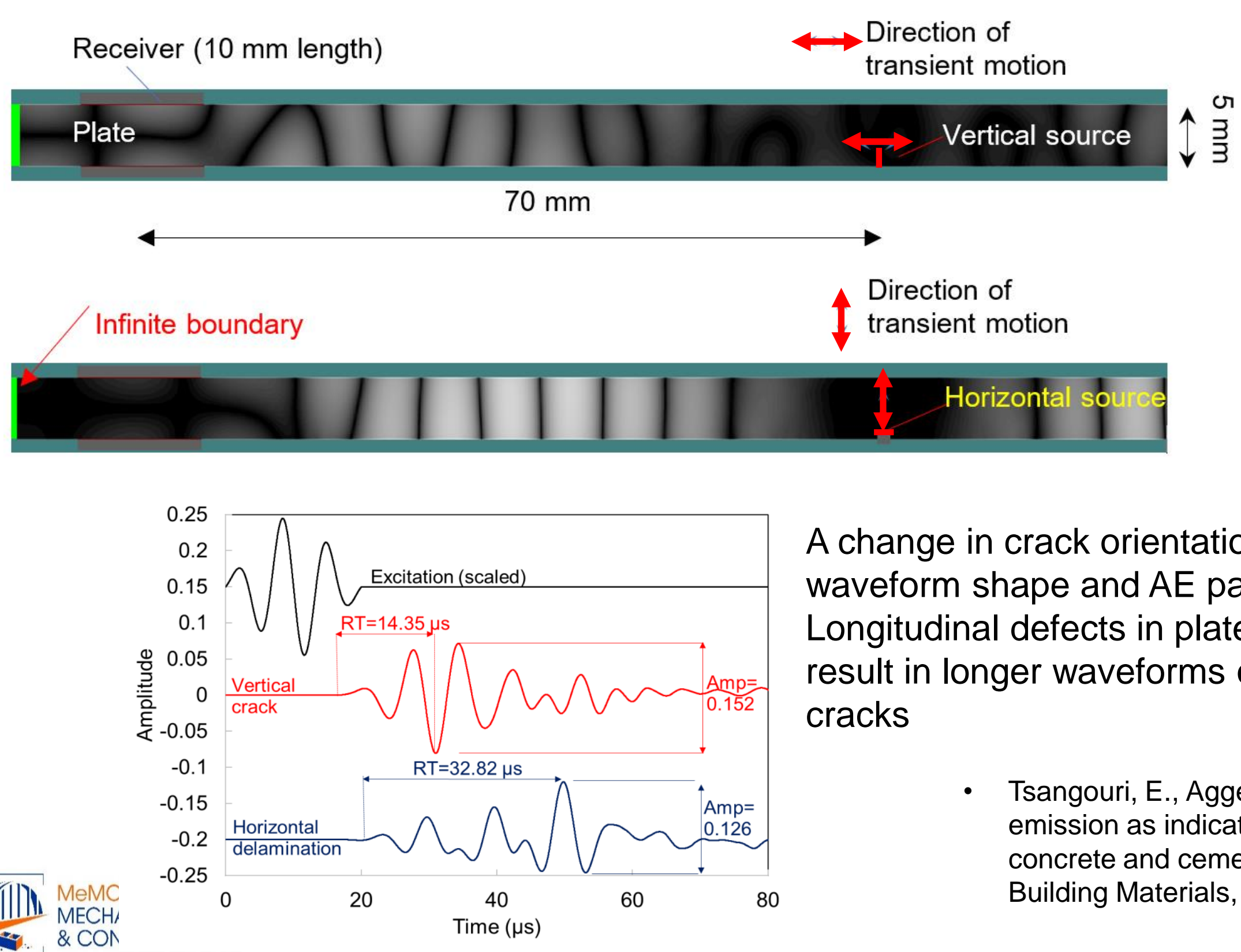

A change in crack orientation results in different waveform shape and $A E$ parameters.

Longitudinal defects in plates (usually delaminations) result in longer waveforms of lower frequency than matrix cracks

- Tsangouri, E., Aggelis D.G., A review of acoustic emission as indicator of reinforcement effectiveness in concrete and cementitious composites, Construction and Building Materials, 224, 10 2019, Pages 198-205 
Tensile tests on 3D printed Onyx and Nylon specimens
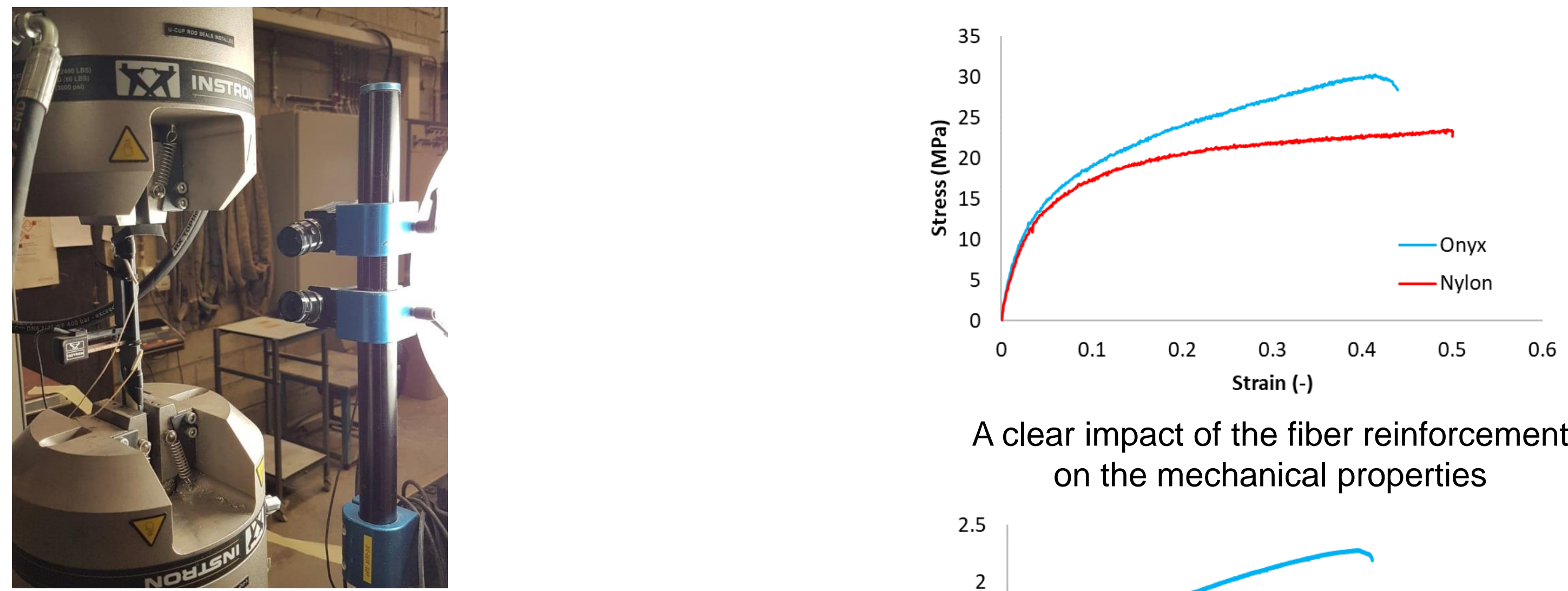

- Quasi-static tests

- $1 \mathrm{~mm} / \mathrm{min}$ displacement rate

- Test until a displacement of $60 \mathrm{~mm}$ or final failure

- $30 \mathrm{~dB}$ AE amplitude threshold

- $50 \mathrm{~mm}$ distance between sensors

A clear impact of the fiber reinforcement on the mechanical properties

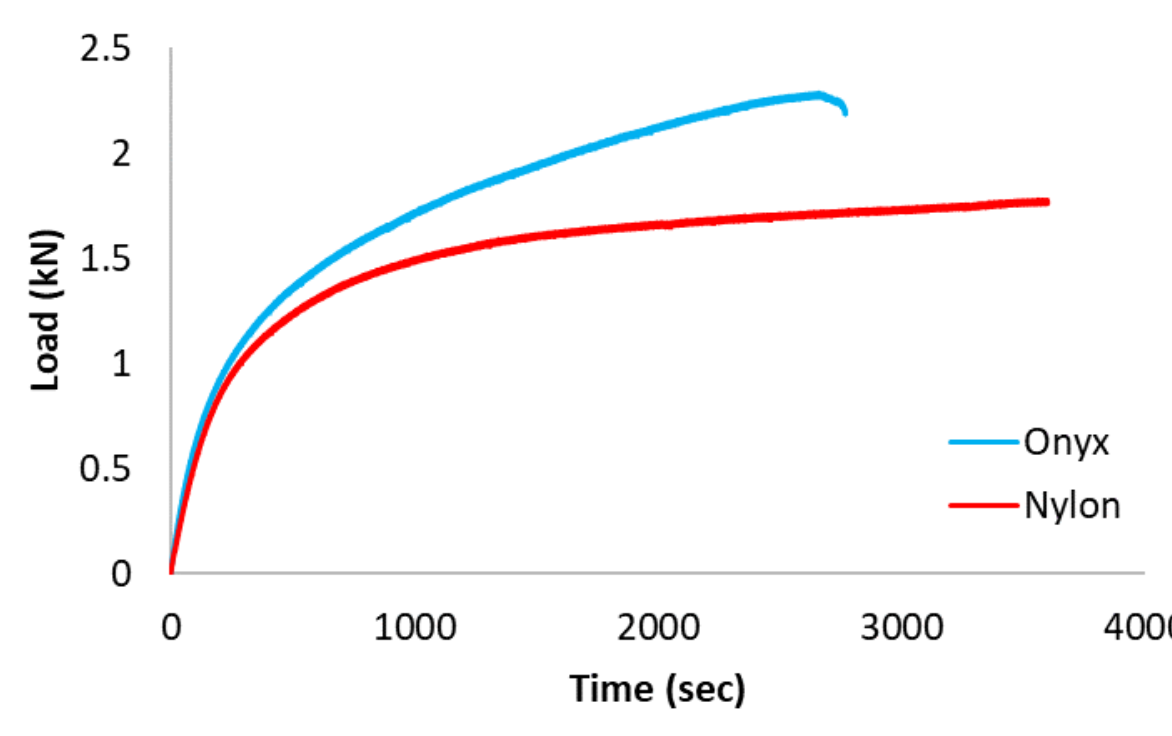




\section{Tensile tests on Onyx and Nylon specimens}

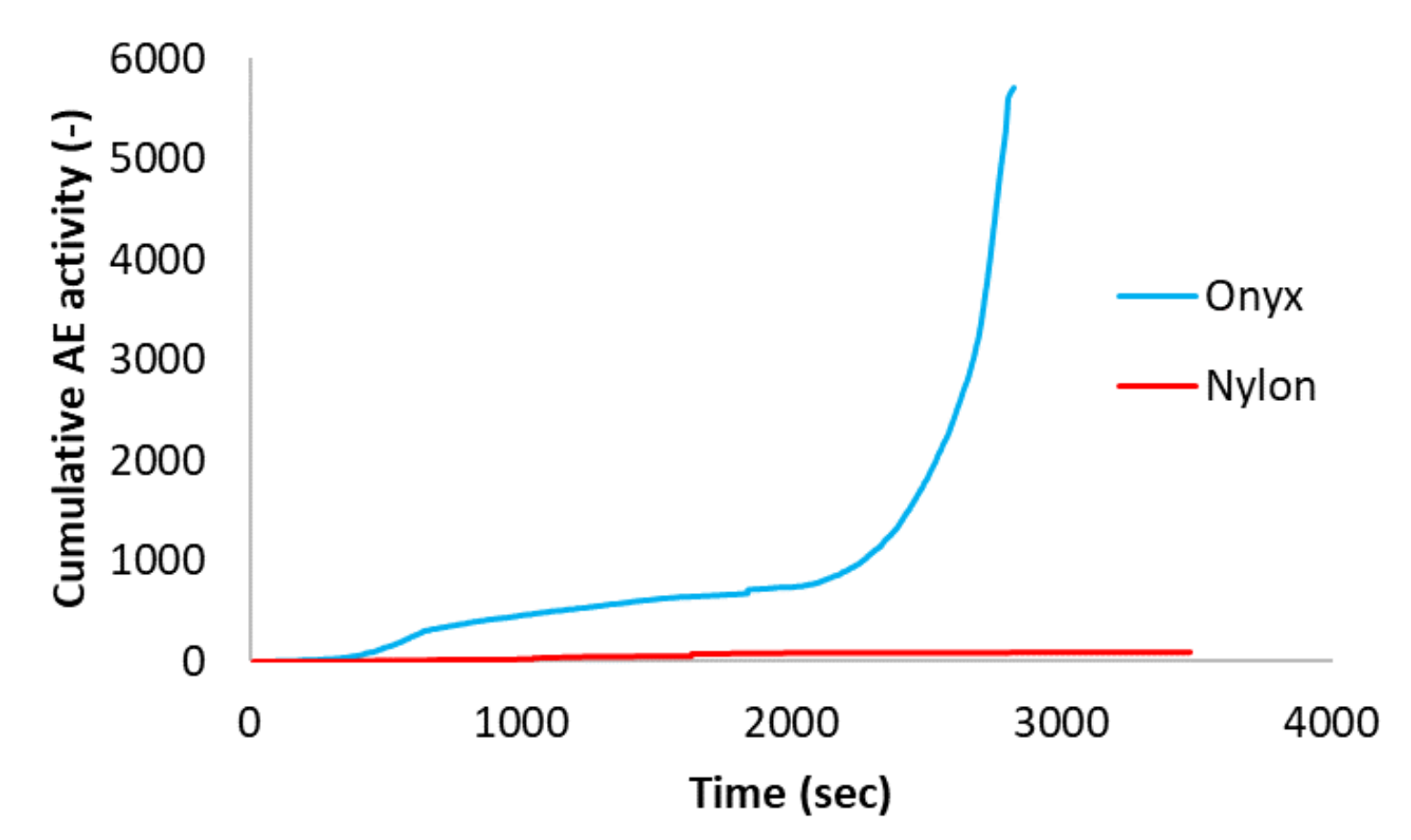

Zoom-in for Nylon specimens

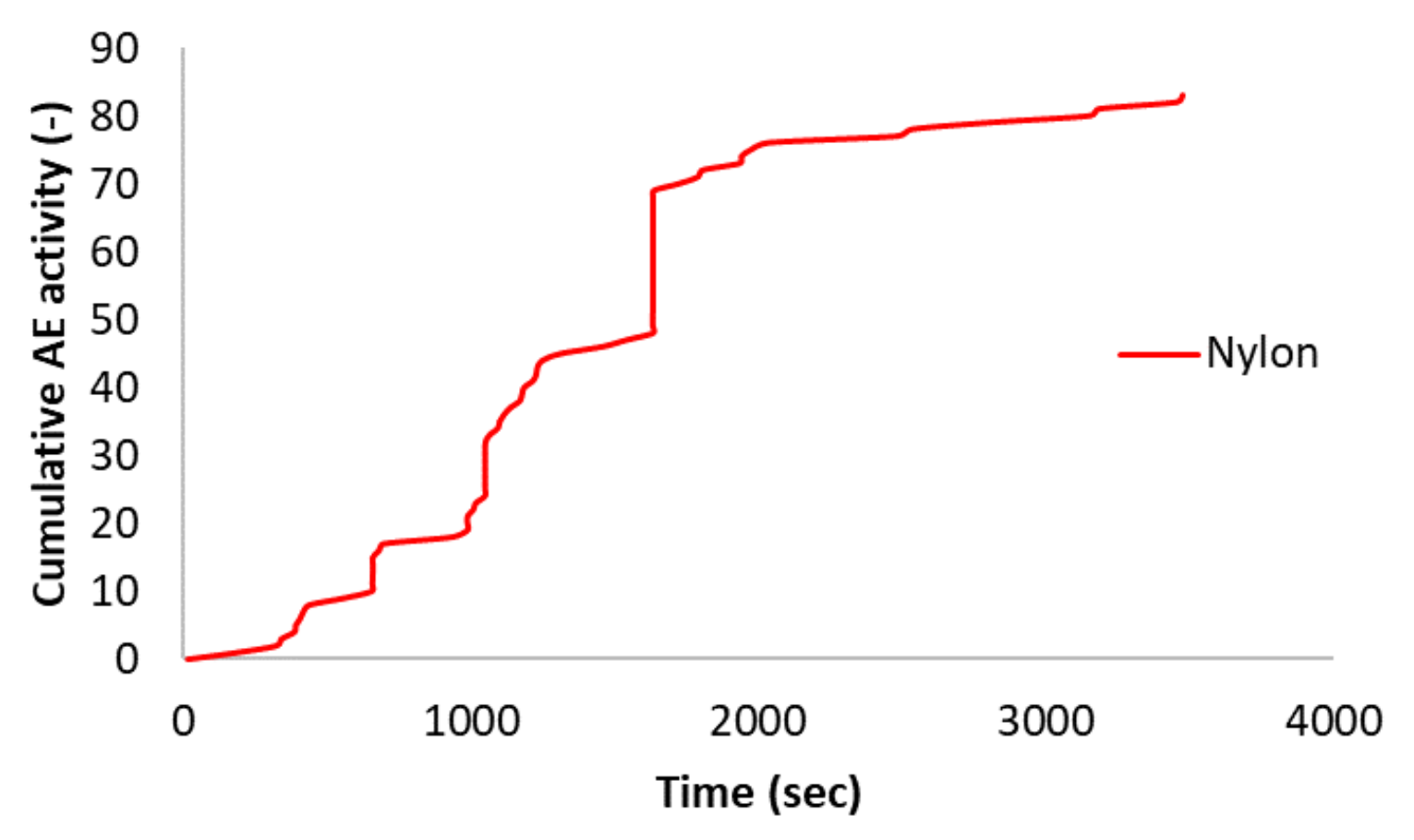

A great difference in the cumulative AE activity 


\section{Tensile tests on Onyx and Nylon specimens}
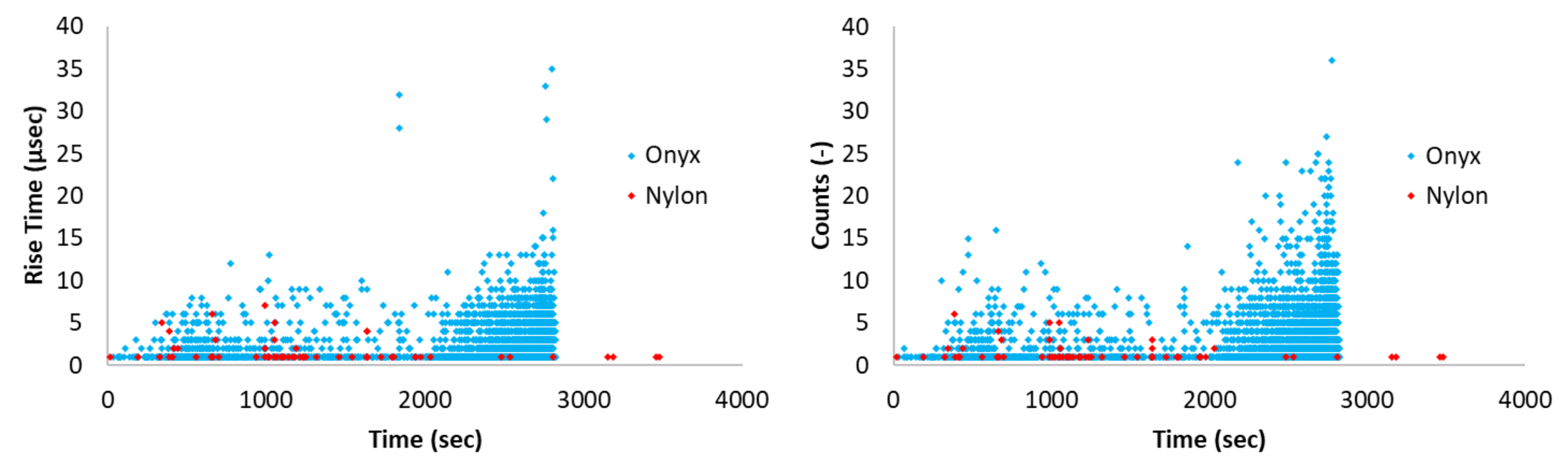

The presence of fibers leads to higher values of the rise time and the number of counts from early loads 


\section{Tensile tests on Onyx and Nylon specimens}
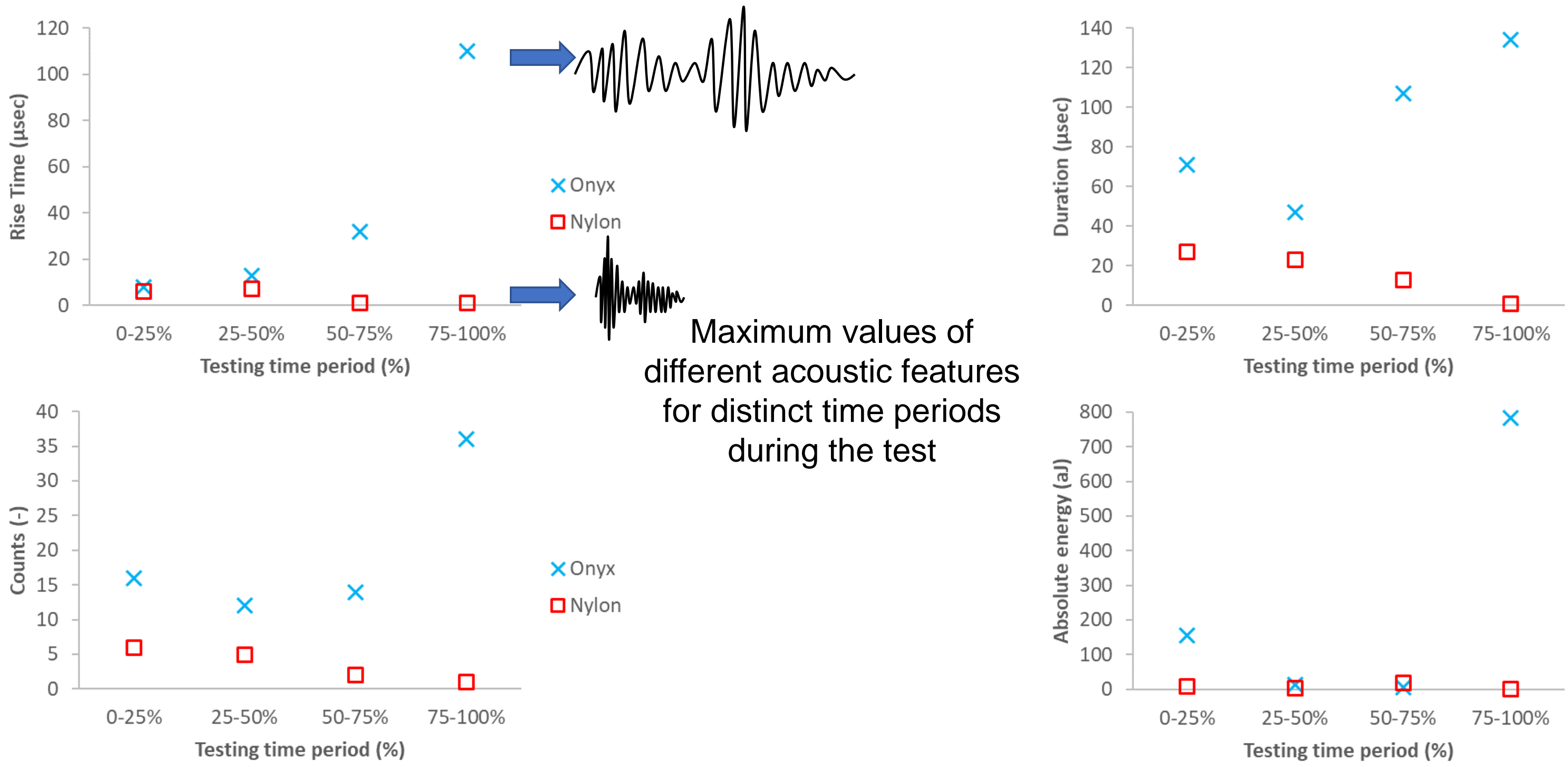

$\times$ Onyx

$\square$ Nylon

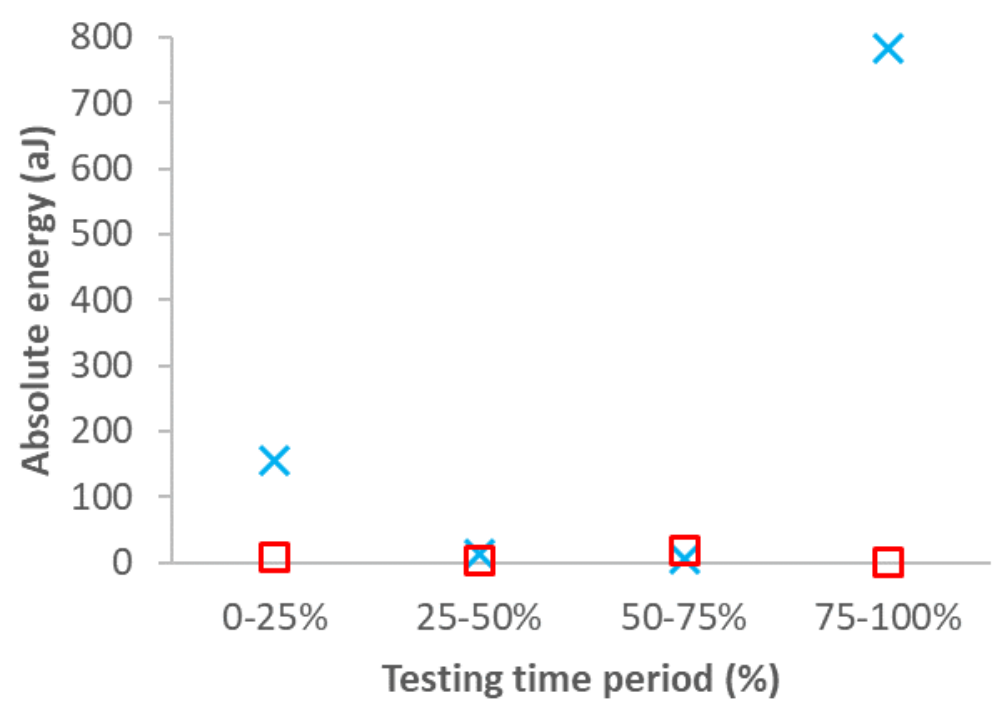




\section{Fracture of $3 D$ TRC under bending}

Composite $=$ Matrix +

Reinforcement

Fine grained (in)organic cementitious matrix

Fibers cover

Design of thin elements

Easily pourable through fibers

AR glass textile mat (3\%v.f.) Orthogonal or randomly distributed fibers 2D or 3D structure Optimized waving design
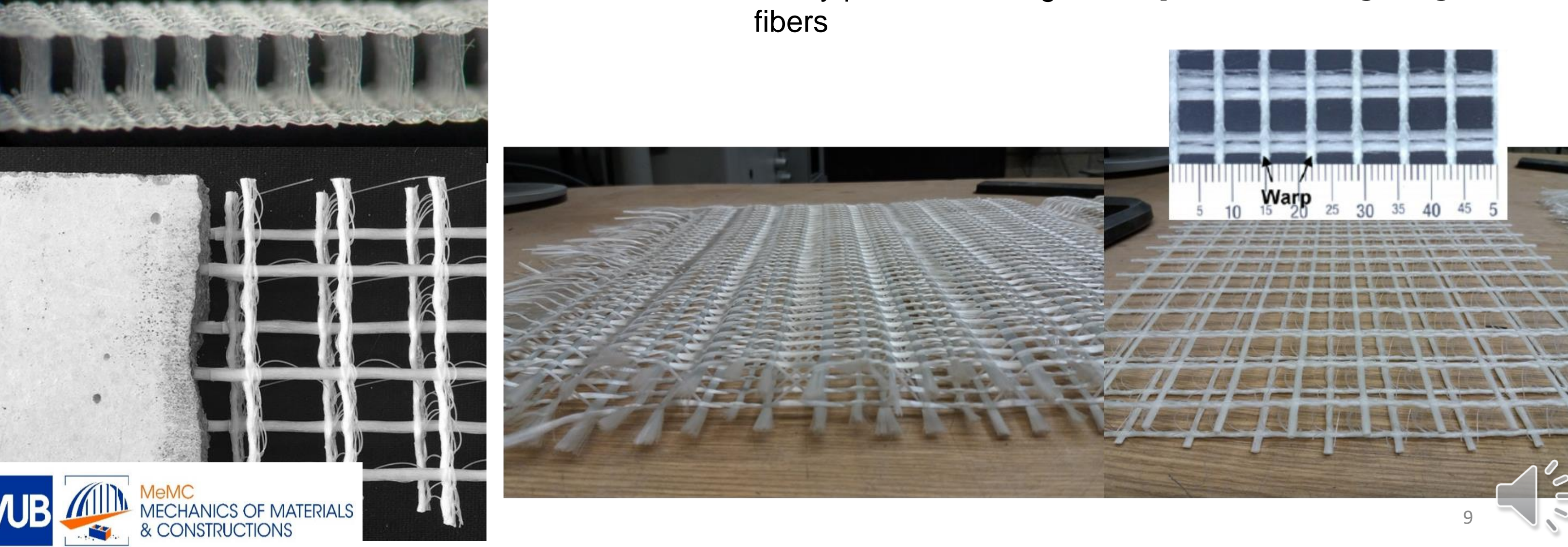


\section{Influence of fiber pattern (3D/2D) on mechanical behavior}
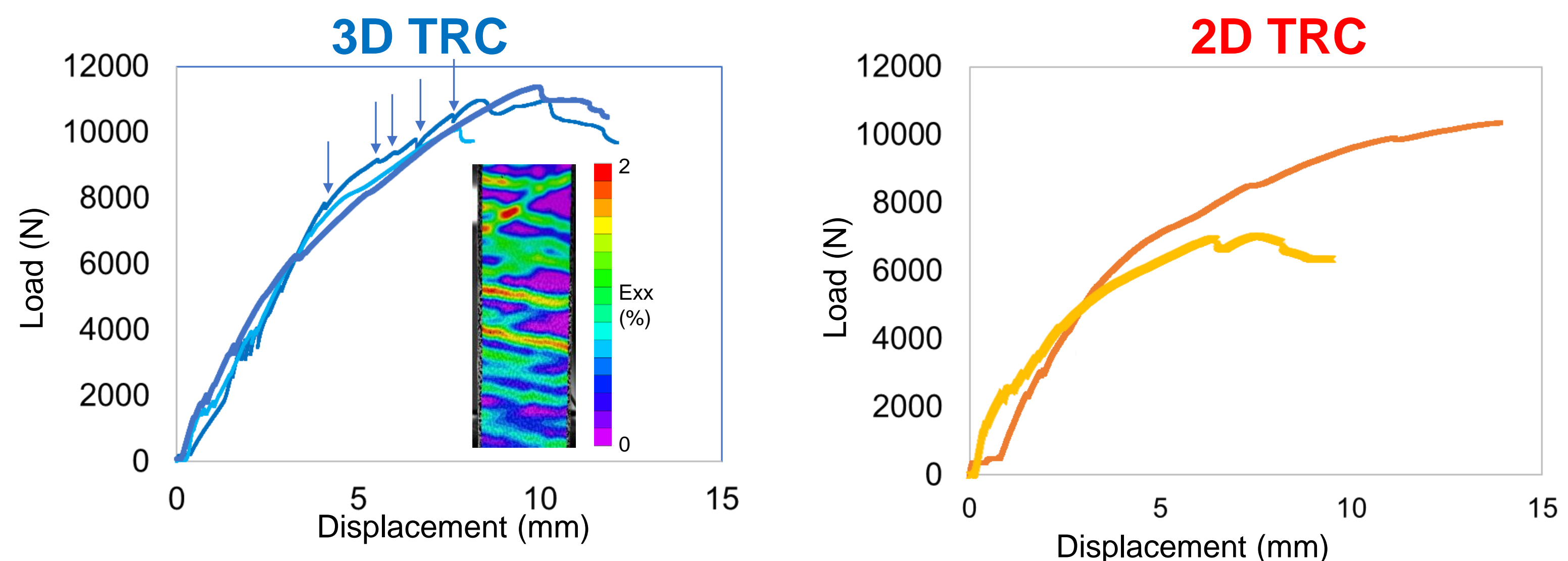

3D has more consistent behavior resulting in more cracking and some higher capacity

- Tsangouri, E., Michels, L., El Kadi, M., Tysmans, T., Aggelis, D.G., A fundamental investigation of textile reinforced cementitious composites tensile response by Acoustic Emission (2019) Cement and Concrete Research, 123, art. no. 105776, DOI: 10.1016/j.cemconres.2019.105776 


\section{Influence of fiber pattern (3D/2D) on $A E$}
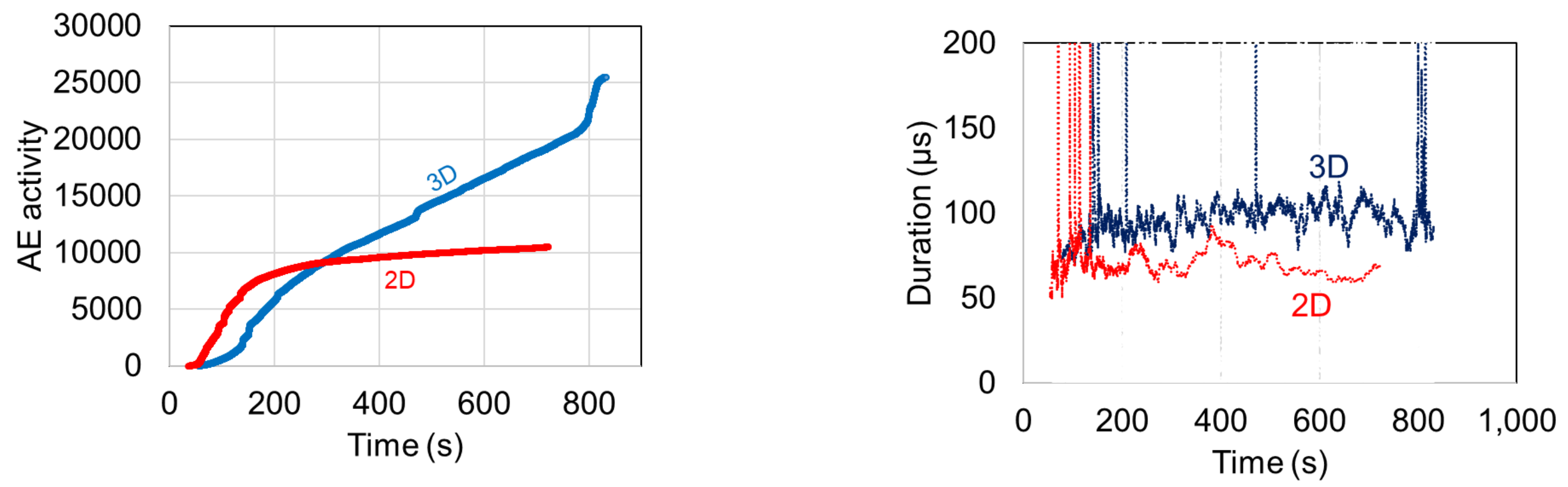

\begin{tabular}{l|c|c|c|}
\cline { 2 - 4 } & Averages & DUR $(\mu \mathrm{s})$ & $\mathrm{AF}(\mathrm{kHz})$ \\
\hline $\begin{array}{l}\text { of the reinforcement, even from the start } \\
\text { (from 200 initial hits) }\end{array}$ & 3D & 80.5 & 165.4 \\
\hline
\end{tabular}

- Michels, L., Tsangouri, E., El Kadi, M., Tysmans, T., Aggelis, D.G. (2018), 3D Textile Reinforced Cements: $A E$ inspection of the fracture of this innovative construction material, in Progress in Acoustic Emission XIX, Eds. T. Shiotani, Y. Mizutani, H. Yuki, pp.173-178. 


\section{Influence of fiber type (Carbon/Glass) on AE}

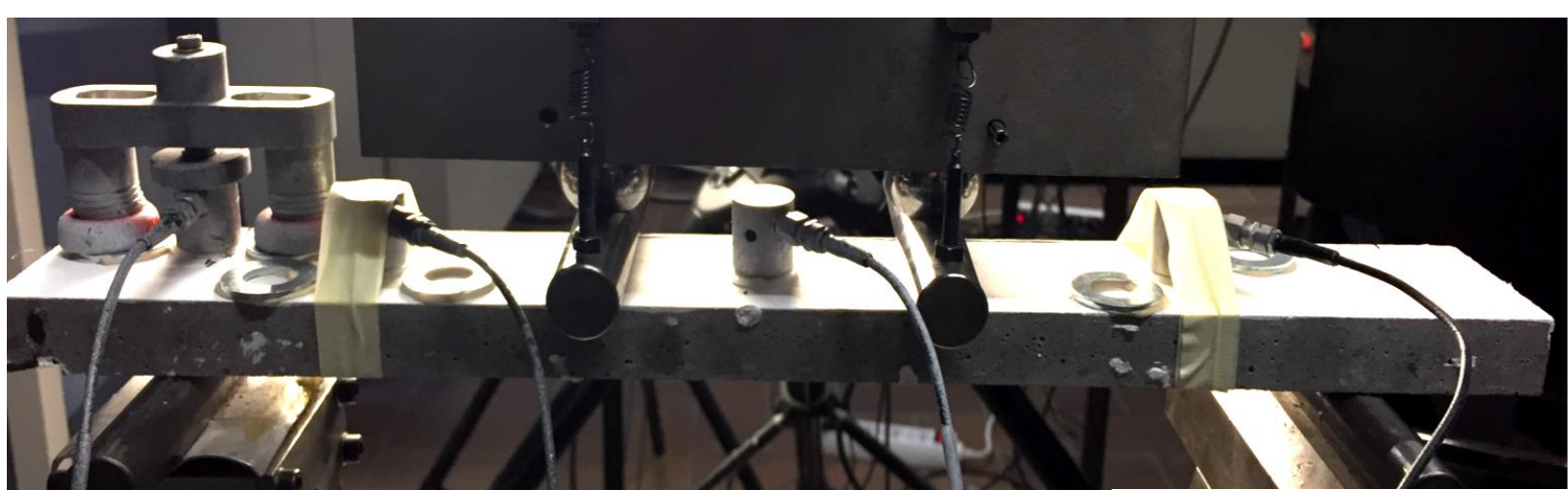

1400

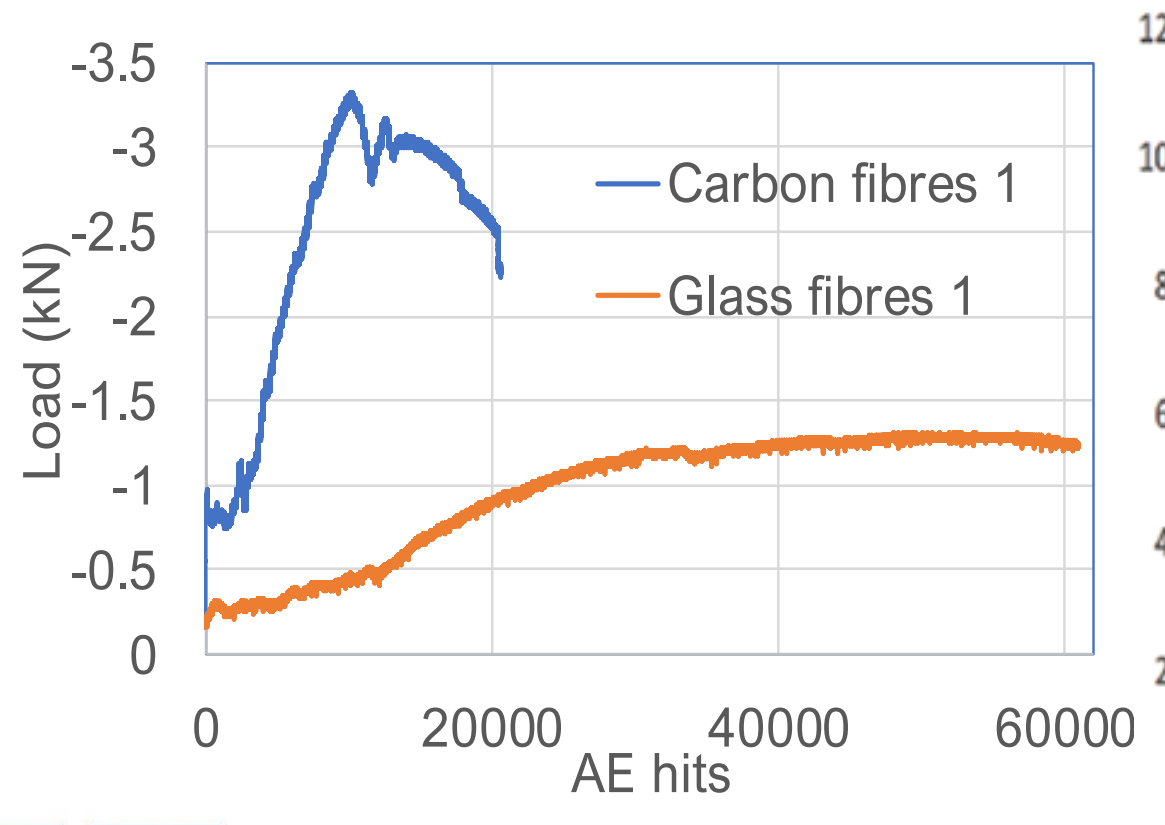

UB
1200

1000

800

600

400

200

0

AE in bending of 3D-TRC with Carbon or Glass fibres.

Carbon fibres result in much higher ultimate load

Also in much higher RA even from the early loading, due to more effective reinforcement effect.

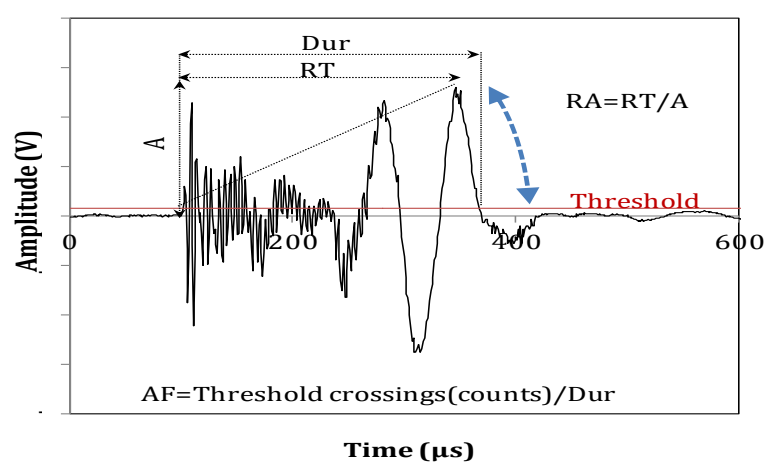

Lin. Load M. Cracking Load Incr. Plateau

(b) $\mathrm{RA}(\mu \mathrm{s} / \mathrm{V})$ 


\section{Conclusions}

The effect of the reinforcement is shown early in the AE behavior by more "shear" characteristics)

3D pattern in cement composites helps to distribute the cracking

In 3D printed polymer composites the effect of fibers is similar and evident from the early stages of loading.

RA value of early AE seems indicative of the effectiveness of the reinforcement

The final performance of the composite can be evaluated by the AE during a low proof loading

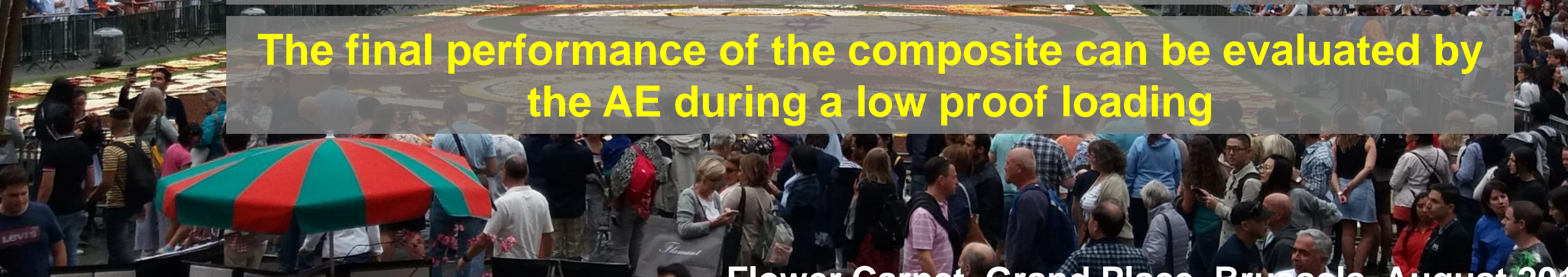

Flower Carpet, Grand Place, Brussels, August 2018 


\section{Thank you}

\section{daggelis@vub.be}

\section{fWO opening new horizons}

Financial support of FWO (Fonds Wetenschappelijk Onderzoek-Vlaanderen, projects number G.0C38.15, $12 \mathrm{~J} 7720 \mathrm{~N}, \mathrm{G} .0090 .1$ ) is gratefully acknowledged.

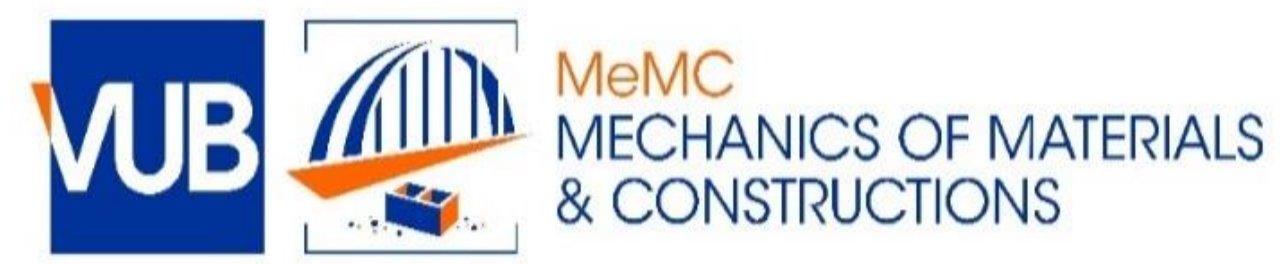

